\title{
Um importante encontro: música e ciências sociais
}

[ A critical reunion: music and social sciences)

Eduardo Tadafumi Sato ${ }^{\mathrm{T}}$

[ FERNANDES, Dmitri Cerboncini; SANDRONI, Carlos (Orgs.). Música e ciências sociais: para além do descompasso entre arte e ciência. Curitiba: Prismas, 2016.

Do que falamos quando falamos sobre música? Uma pergunta desse tipo aparenta ter uma resposta direta e imediata, pois todos parecemos ter uma concepção clara sobre o que a música é. Afinal estamos cercados durante todo o tempo por sons e classificamos alguns deles nessa categoria. Ouvimos música, por exemplo, no rádio do carro, em reprodutores portáteis (iPod, celular), no computador, na televisão, nos filmes, na cidade, em shows e concertos. Será que em termos analíticos podemos chamar tudo isso de música? Quando falamos de uma partitura, de uma gravação, do som produzido por um instrumento, de um gênero musical, estamos nos referindo à mesma coisa? A existência de diferentes áreas que estudam a música e as diferentes conceituações que possuem sobre ela parecem indicar uma resposta negativa para a questão. Quando consultamos estudos especializados sobre o tema, percebemos que a definição do que é música se faz em cada caso particular e, portanto, trata-se de uma questão aberta e que necessita de respostas e reformulações constantes. Limitar a discussão para a relação entre música e sociedade afunila o tema, porém ainda são diversas as abordagens possíveis, especialmente porque esse tópico, compreendido a partir de uma visão científica, é ainda recente.

SATO, Eduardo. Um importante encontro: música e ciências sociais. Revista do Instituto de Estudos Brasileiros, Brasil, n. 66, p. 240-245, abr. 2017.

DOI: http://dx.doi.org/Io.II6o6/issn.23I6-90IX.voi66p240-245

I Universidade de São Paulo (USP, São Paulo, SP, Brasil). 
Nesse sentido, o livro Música e ciências sociais traz uma importante contribuição aos estudos sobre música no Brasil ao apresentar, em português, alguns importantes debates sobre uma área de pesquisa em consolidação no país ${ }^{2}$. A proposta de aproximar a música das ciências sociais tem como intenção estabelecer um laço que parece distante entre dois campos: de um lado a arte e do outro a ciência. O volume organizado por Dmitri Fernandes e Carlos Sandroni propõe aproximar a análise de concepções diversas sobre a música, sempre em relação a algum referencial social, de uma análise científica, empreitada que pareceu paradoxal na academia brasileira. Trata-se de entender a música como objeto legítimo de uma análise científica, não somente na sua linguagem própria e codificada, mas nos meios sociais em que se inscreve; e também de legitimá-la como objeto das ciências sociais. O impasse para o qual se busca uma solução é a ideia da cisão entre a arte - no caso, a música como objeto de um julgamento estético e não objetivo e universalizável - e a ciência - análise objetiva com a qual a apreciação subjetiva não se enquadra. A problematização da questão é proposta no livro em II artigos, frutos do I Simpósio Internacional Música e Ciências Sociais, realizado em 20I3 na Universidade Federal de Juiz de Fora. A primeira parte é composta de textos que têm o foco em questões mais ligadas aos métodos de pesquisa ou metodologia; na segunda, a pesquisas têm como foco algum objeto musical mais específico, como gêneros e práticas musicais. Apesar da predominância de artigos ligados à área da sociologia, o volume apresenta

2 Vale lembrar que esse esforço de sistematizar pesquisas sobre música e ciências sociais também tem sido realizado em outras partes do mundo, como na revista Music and arts in action, liderada por Tia DeNora na Inglaterra, ou no importante artigo "What is sociological about music?", de William Roy e Timothy Dowd nos Estado Unidos. ROY, William G.; DOWD, Timothy. What is Sociological about Music?. Annual Review of Sociology, 36, 2010, p. I83-203. 
um sentido amplo do termo "ciências sociais", abrangendo áreas irmãs como a história, a antropologia e as relações internacionais3.

O artigo de Frederico Barros, "Sociologia da música: entre o rigor historicista e a crítica de arte", que abre o livro, trata diretamente da questão central proposta pelos organizadores. Ao dialogar com a bibliografia internacional sobre o tema, de autores como Howard Becker e Antoine Hennion, apresenta uma densa discussão metodológica. A proposta de uma sociologia da música que não seja uma simples análise social da música, que é tendência predominante quando a sociologia trata de objetos artísticos, depende de cuidados de se interpretar tal objeto multidimensional entendendo suas especificidades. Não se trata, porém, de uma análise pura da linguagem musical, polo que o autor associa com a crítica de arte, mas de buscar um caminho intermediário que ofereça um equilíbrio entre as duas vertentes. Partindo do caso das suas pesquisas sobre o compositor César Guerra-Peixe, Barros mostra que questões associadas à música do compositor, como mudanças no seu estilo, não podem ser reduzidas à circunstância social, nem às obras em si, mas devem ser entendidas a partir da dinâmica produzida entre ambas. Ao apresentar abordagens teóricas da história, literatura, sociologia e história da arte, o sociólogo propõe a necessidade de uma abertura ao diálogo e colaboração nas pesquisas sobre música, enfatizando a pertinência da interdisciplinaridade.

Em "Fora de moda e sem lugar: rádio e cultura na formação da escola uspiana (I960-I970)", Marc Hertzman verifica o lugar ocupado pelas investigações sobre o rádio e a cultura na década de I960 nos estudos sociológicos na Universidade de São Paulo, momento da constituição da escola uspiana, liderada principalmente por Florestan Fernandes. O pesquisador norte-americano, ao analisar o livro Cor, profissão e mobilidade: o negro e o rádio de São Paulo, de João Baptista Borges Pereira, apresenta esse tema como "fora de moda", uma vez que, apesar de o livro trazer o termo rádio no título, não há interesse em estudar a música, mas utilizá-la como pressuposto para analisar questões mais amplas como as relações raciais e a estrutura social. Os comentários que Hertzman realiza sobre o trabalho de Pereira mostram como essa pesquisa estava associada à proposta científica daquele momento em termos de método, ao mesmo tempo que se afastava dela pelo objeto de pesquisa.

Os estudos sobre a música e as relações internacionais, perspectiva nova mesmo em âmbito mundial, são abordados, no artigo "Música e relações internacionais: o Conselho Internacional da Música, a Unesco e a Guerra Fria”, por Anaïs Fléchet, que oferece um panorama dessa abordagem ${ }^{4}$ e segue com um estudo sobre o caso do

3 Essa tendência de explorar disciplinas das humanidades para estudar a música pode ser verificada em diversos eventos acadêmicos realizados nos últimos anos, dos quais podemos destacar a I Jornada de Estudos Interdisciplinares sobre Música realizada no Instituto de Estudos Brasileiros da Universidade de São Paulo em 20I5. Carlos Sandroni, na “Apresentação" ao livro (p. 9), traz exemplos de associações e eventos científicos que trazem uma perspectiva social para a música.

4 Vale mencionar os três eixos temáticos que são apresentados como vertentes das pesquisas atuais: a circulação dos músicos e das obras; as políticas públicas dos Estados e das organizações internacionais, discutindo a noção de “diplomacia musical”; e a música em tempos de guerra e de paz (p. 84). 
Conselho Internacional de Música (CIM), órgão ligado à Unesco, entre I945 e I975. A historiadora francesa mostra que a música foi mobilizada durante a Guerra Fria como instrumento para a paz, no nível das disputas e cooperações entre as nações. A atuação do CIM como órgão internacional independente buscava utilizar a música como mobilizadora dos homens para além dos interesses nacionais, que muitas vezes cerceavam a circulação de artistas e práticas musicais.

O artigo de Dmitri Fernandes - "Margeando a cultura: o samba e o choro em sua bibliografia própria" - questiona a produção das fontes utilizadas na construção da história do samba e do choro. Ele mostra como os "escritores nativos", músicos, jornalistas e cronistas simultaneamente participantes das narrativas sobre a música, apresentaram uma visão comprometida na constituição de uma história desses gêneros musicais, formando um cânone ligado a interesses particulares. Essa tese não busca desqualificar esses relatos nativos, mas contestar as pesquisas que não realizam o processo de crítica das próprias fontes, de modo que compreendem como verdade discursos que precisam ser questionados nos contextos específicos. Essa perspectiva traz uma grande contribuição para os novos estudos nessa área como importante fonte metodológica.

A análise de Charles Kischbaum sobre músicos de jazz norte-americanos apresenta, no texto "Uma aplicação de métodos quantitativos para 'música e ciências sociais': redes e estilos no jazz”, a proposta da utilização de métodos quantitativos nas análises sobre música, que não são comuns no Brasil. Trabalhando com uma enorme quantidade de dados que engloba a discografia do jazz e seus músicos de I930 a I969, o pesquisador mapeia as "redes de afiliação" entre os músicos, o que permite testar hipóteses sobre a circulação e colaboração deles em gravações a respeito da relevância da raça, do gênero e do estilo.

A segunda parte do livro, denominada "Música em ação", é aberta pelo artigo de Felipe Trotta, "O 'popular' na música televisiva: os casos de Cheias de charme e Avenida Brasil", que estabelece um vínculo entre as representações sociais presentes em telenovelas e as músicas ali veiculadas. Entendendo o grande número de pessoas atingidas por tal linguagem comunicativa e o seu papel na difusão das músicas ali veiculadas, o pesquisador estabelece um vínculo entre a representação de camadas populares na linguagem televisiva e as canções utilizadas na sua composição. São, assim, várias camadas analisadas com referências aos contextos de produção das músicas, aos depoimentos dos artistas, à análise das letras e à própria representação da música no enredo de uma das novelas. Ao mobilizar as ideias de "periferia", não somente no sentido geográfico apresentado na narrativa, mas também como termo analítico carregado de significados estigmatizados, em contraste com o centro, a proposta é discutir o conceito de "popular", que passa por uma ressignificação na indústria cultural atual. Trotta chama a atenção para a "sensação de periferia", com a conotação positivada que é criada nesse circuito entre produtores, enredo e espectadores, e que se vincula a posições e tensões sociais continuamente negociadas.

Seguem-se artigos que de diferentes maneiras lidam com gêneros musicais, trazendo à tona discussões sobre a sua delimitação, suas práticas e seus usos. As abordagens distintas respondem às diferentes maneiras como os autores concebem o seu objeto de pesquisa, de modo que agrupá-los a partir da noção de gênero musical 
é uma simplificação que não dá conta dessa diversidade e não valoriza as maneiras próprias dos autores de desenvolverem os seus trabalhos.

"O sertão universitário", de Gustavo Alonso, apresenta o sertanejo universitário entendendo-o como um fenômeno que desafia a concepção comumente utilizada de "indústria cultural", emergido a partir da metade dos anos 2000 com o aumento do acesso à internet e às redes sociais no Brasil. Essa mudança tecnológica aproximou os músicos do seu público, diminuindo a influência de mediadores tradicionais na área, como as gravadoras. Dialogando com o artigo de Felipe Trotta, Alonso atribui a ascensão do gênero à inserção em trilhas sonoras de telenovelas, além da sua consolidação a partir da colaboração com nomes já estabelecidos na cena musical. A análise que realiza de canções e depoimentos dos músicos, apresentando variados exemplos, permite emoldurar características que conformam um novo tipo de sertanejo5, que em geral foi tópico ignorado pela academia como tema de pesquisa, apesar da denominação "universitário".

Em "Modernismo, tropicália e manguebeat: antropofagia musical brasileira em três atos", Arthur Bezerra lê a ideia de antropofagia - entendida como "renovação cultural a partir da mistura de elementos de origem local com outros de origem externa" - como mote organizador da música brasileira ao longo do século XX, verificando-a em três momentos históricos: o Modernismo da década de I920, a tropicália nos anos I960 e o manguebeat na última década do século. Partindo mais de ideias gerais do que de análises mais próximas aos objetos de que trata, Bezerra realiza um voo sobre importantes momentos da música no Brasil.

O artigo que se segue, "Estruturas sociais do amor e do sexo e as emoções eróticodançantes no pagode baiano”, de Fernando Rodrigues, aborda o pagode baiano e as maneiras como estão ali incorporadas as estruturas sociais das relações interpessoais e sexuais nas práticas desse gênero. Para tanto, utiliza-se de uma descrição minuciosa de um vídeo que retrata uma performance. Essa perspectiva assume a ideia do pagode baiano não como um gênero musical que pode ser delimitado na música enquanto som, mas localizado na sua performance, que pressupõe determinadas condições para a realização.

Já Elder Maia, em "Arte, técnica, mercado e memória: o gênero musical baião", questiona o gênero do baião, hoje consolidado como produto autêntico da cultura nacional. Ele atribui a formação do gênero a dois principais agentes: Luiz Gonzaga e Humberto Teixeira, especialmente com a transmissão do programa radiofônico No mundo do baião, veiculado na Rádio Nacional entre I95I e I953. Delimitando alguns dos interesses que possibilitaram a criação desse gênero e sua associação com um imaginário sobre o Nordeste brasileiro, Maia se aproxima da proposta de Dmitri Fernandes de contestar a história de tradições musicais no Brasil, mostrando como relatos nativos precisam ser desconstruídos pelas pesquisas.

O artigo que encerra o livro, "E chore quem quiser chorar': uma experiência etnográfica do ensino da música popular”, assinado por Marina Frydberg, difere dos anteriores por ser o único que apresenta uma etnografia, no caso, uma descrição da

5 Propõe três temáticas para o sertanejo universitário: a "poética do amor afirmativo", a "poética da farra” e a "poética do 'tô nem aí” (p. 204). 
aprendizagem do choro no Festival Nacional do Choro e na Escola Portátil de Música. Ao observar a formação de um músico de choro a partir de vivências que vão além das aulas de instrumentos, a autora apresenta reflexões sobre a prática musical, os modos de transmissão do conhecimento e a divisão de gêneros ali presente. Não se trata de uma história do choro a partir de seus autores e obras consagradas, mas como resultante de uma pesquisa que enfoca uma narrativa oral, maneira pela qual o aprendizado musical era tradicionalmente realizado, sugerindo novos meios para reprodução e perpetuação dessas práticas.

Essa iniciativa precursora de sintetizar a produção sobre música e ciências sociais no Brasil é importante para estimular um campo de estudos ainda incipiente. A abertura ao diálogo que propõe esse tipo de empreendimento permite um adensamento em termos metodológicos em um cenário acadêmico que começa a desbravar, a despeito de dificuldades institucionais, a importante área da interdisciplinaridade nas pesquisas. Porque, quando se trata de música, ainda há objetos em diversidade e quantidade para pesquisadores de muitas gerações.

SOBRE O AUTOR

EDUARDO TADAFUMI SATO é mestre em Estudos Brasileiros pelo Instituto de Estudos Brasileiros da Universidade de São Paulo.

E-mail: dutsatoI@gmail.com 